\title{
PESSOA COM DEFICIÊNCIA, MERCADO DE TRABALHO E ATUAÇÃO DAS APAES NAS PUBLICAÇÕES CIENTÍFICAS
}

Renata dos S. S. Bobadilha ${ }^{1}$

\section{RESUMO}

O presente trabalho tem como objetivo investigar e analisar as publicações científicas relacionadas às ações da Rede Apae e ao encaminhamento da pessoa com deficiência para o mercado de trabalho. Visando embasar a construção deste texto, realizou-se um levantamento bibliográfico, com a finalidade de localizar documentos que narrassem sobre os temas: mercado de trabalho e Apae. Foram localizadas 13 publicações nesse sentido. Apesar da escassa produção científica vinculando esses dois temas, realizamos a análise dos resumos da literatura encontrada, buscando identificar a importância das ações da Apae no contexto do mercado de trabalho das pessoas com deficiência. Os resultados demonstram que, ainda que não se revele intensa a preocupação com essa problemática, a questão sobre o trabalho vem adquirindo destaque nas reflexões e estudos de pesquisadores. Ademais, as ações da APAE vêm ganhando evidência devido à sua importância para o preparo, encaminhamento e acompanhamento das pessoas com deficiência para o exercício laboral, trazendo reconhecimento sobre as suas potencialidades e a luta contra a exclusão.

Palavras-chave: Mercado de Trabalho. Apae. Pessoa com Deficiência.

\begin{abstract}
This study aims to investigate and analyze the cientific publications related to the actions of APAE and to the referral of the person with deficiency to the job market. Aiming to support the construction of this text, we did a bibliographic survey, in order to locate documents that tell about: job market and APAE. There were located 13 publications. Aside from this poor cientific production connected with these two topics, we analyzed the abstracts of the literature found, seeking to identify the importance of the actions of APAE in the context of the job market of people with deficiency. The results demonstrate that, despite there is no intensive concern about this problematic, the point about the job is becoming relevant in the reflexions and studies of the researchers. Furthermore, the actions of APAE are being more important because of its preparation, referral and monitoring of people with deficiency to the job exercise, bringing recognition about their potential and fight against the exclusion.
\end{abstract}

Keywords: Job Market. APAE. Person with Deficiency.

\section{INTRODUÇÃO}

\footnotetext{
${ }^{1}$ Licenciada em Educação Musical em 2013, pela Universidade Federal de Mato Grosso do Sul. Membro do Grupo de Estudos e Pesquisa em Inclusão e Educação Especial - GEPIEE/UFMS.
}

Fed. Nac. das Apaes- Fenapaes $\mid$ Brasília/DF | v.10| no2 | P. 22 - 38 | jul./dez.2018 | ISSN 2237-4329| 


\section{Apøe Ciênci@ Artigo}

A trajetória do movimento de inclusão das pessoas com deficiência (PCD) na sociedade atual foi marcada por várias mudanças. Observando o panorama histórico, nesse sentido, sabe-se que o preconceito com as PCD vem desde a antiguidade. A sociedade "[...] sempre inabilitou os portadores de deficiência, marginalizando-os e privando-os de liberdade. Essas pessoas, sem respeito, sem atendimento, sem direitos, sempre foram alvo de atitudes preconceituosas e ações impiedosas" (MACIEL, 2000, p. 51 apud FERREIRA, 2015). Durante muito tempo, as PCD eram tidas como um peso para carregar, sofrendo exclusão, sendo afastadas do convívio social e consideradas, muitas vezes, como incapazes e segregadas. No que se refere aos cuidados de saúde, as PCD eram de responsabilidade de instituições que ofereciam os cuidados básicos, porém, separadas do meio social.

No decurso dos anos, a luta das PCD foi ganhando força. Era preciso que a sociedade valorizasse e reconhecesse a necessidade da sua inclusão ao convívio social, despertando-se para enfrentar inúmeras formas de preconceito e discriminação, bem como resgastar valores e direitos de cidadania das PCD e promover leis e incentivos à educação, ao trabalho e outras atividades.

Na segunda metade da década de 1980, o movimento em favor de uma sociedade inclusiva, veio tomando maiores proporções. No entanto, somente na década de 1990, pela Declaração de Dakar (Declaração Mundial sobre Educação para Todos), realizada na Tailândia, o movimento de Educação Inclusiva teve o seu marco. Sobretudo, é importante afirmar que, foi na "Conferência Mundial sobre Necessidades Educacionais Especiais: Acesso e Qualidade”, realizada em 1994, em Salamanca - Espanha, que foi instituído o compromisso, o acesso à educação das Pessoas com Deficiência e o direito à educação, uma Educação para Todos (BENJAMIN, 2013). Esse compromisso ficou conhecido como a Declaração de Salamanca.

Nessa Declaração, dois pontos são ressaltados. Primeiro, a criança tem direito fundamental à educação. Segundo, as crianças com necessidades educacionais especiais devem ter acesso à escola regular, em local livre de discriminações. Nessa declaração houve o entendimento da necessidade de inclusão e não integração, termo tratado no início deste texto. Nesse sentido, a Educação Inclusiva na Declaração de Salamanca parece utópica. Segundo Werneck (1999, p. 213, apud BENJAMIN, 2013) se é utopia pensar numa "Sociedade para Todos, faz bem continuar sonhando uma sociedade inclusiva, onde TODOS, mas TODOS mesmo sejam incluídos". Dessa maneira, para ser real esse modelo de educação, torna-se imprescindível a concretização de um ensino público de qualidade, a formação profissional, a valorização dos profissionais da educação, bem como a 
formação continuada, a elaboração de políticas públicas de acesso e a permanência para todas as pessoas sem discriminação, e outros.

Nessa perspectiva, também podemos apontar alguns avanços no Brasil nesse sentido. A Constituição da República Federativa do Brasil, de 1988, no seu art. $5^{\circ}$ trata sobre o princípio da igualdade.

Art. $5^{\circ}$. Todos são iguais perante a lei, sem distinção de qualquer natureza, garantindo-se aos brasileiros e aos estrangeiros residentes no País a inviolabilidade do direito à vida, à liberdade, à igualdade, à segurança e à propriedade [...].(BRASIL, 1988).

Outro exemplo referente à defesa dos direitos da pessoa com deficiência é tratado nos $\operatorname{artigos} 6^{\circ}$ e $7^{\circ}$ da Constituição Federal de 1988:

Art. $6^{\circ}$ - São direitos sociais a educação, a saúde, o trabalho, a moradia, o lazer, a segurança, a previdência social, a proteção à maternidade e à infância, a assistência aos desamparados, na forma desta Constituição". [...] Inciso XXXI do artigo $7^{\circ}$ : São direitos dos trabalhadores urbanos e rurais, além de outros que visem à melhoria de sua social: XXXI - proibição de qualquer discriminação no tocante a salário e critérios de admissão do trabalhador portador de deficiência (BRASIL, 1988).

Pode-se observar que, ao longo dos anos, o poder público também realizou algumas iniciativas na área da educação, como na Política Nacional de Educação Especial na Perspectiva da Educação Inclusiva (MEC, 2008): a definição da Educação Especial como modalidade de ensino transversal para todos os níveis, etapas e modalidades de ensino; o estabelecimento de Salas de Recursos Multifuncionais, que contém equipamentos e materiais didáticos e pedagógicos, pelo qual é oferecido atendimento educacional especializado aos alunos com deficiência matriculados na rede regular de ensino, dentre outras realizações (MEC, 2010).

A Lei n ${ }^{\circ}$ 9.394/96, Lei de Diretrizes e Bases da Educação Nacional (LDBEN), avançou no sentido de maior compromisso e acessibilidade à educação, tal como a preparação para uma vida social e profissional. Além de a educação ter como responsabilidade oferecer condições de acesso, um currículo flexível, profissionais especializados para atender os alunos com deficiência, entre outros, a sua atribuição também é encaminhar para o trabalho. Segundo o art. 59, inciso IV, dessa lei, os sistemas de ensino assegurarão aos educandos com deficiência:

Educação especial para o trabalho, visando a sua efetiva integração na vida em sociedade, inclusive condições adequadas para os que não revelarem 
capacidade de inserção no trabalho competitivo, mediante articulação com os órgãos oficiais afins, bem como para aqueles que apresentam uma habilidade superior nas áreas artística, intelectual ou psicomotora (BRASIL, 1996).

Nessa perspectiva, a inclusão das PCD na educação e o direito ao trabalho é uma proposta igualitária e democrática. O artigo 23 da Declaração dos Direitos Humanos (ONU, 2009) evidencia que "toda a pessoa tem direito ao trabalho, à livre escolha do seu trabalho e à proteção contra o desemprego."

Para Dallabrida (2007, apud FURTADO, 2014) é inegável que, além do contexto educacional, posteriormente o do trabalho, torna-se um meio de propiciar o desenvolvimento dessas pessoas, contribuindo também para sua inserção social. Há uma importante ponte nesse processo da educação com o trabalho. Pode-se afirmar que no processo do trabalho continua a formação do homem.

Para Manzini (1996, apud LANCILLOTTI, 2003), discutir a profissionalização das pessoas com deficiência, no qual a autora descreve "deficiência mental", é discutir o ato de integrá-los à sociedade pelo trabalho.

O processo educativo do deficiente mental só estaria completo quando este estivesse incorporado à força do trabalho. [...] se o objetivo que justifica a profissionalização do portador de deficiência mental está claro e o objetivo é integrá-lo à sociedade via trabalho, os processos utilizados para a profissionalização nem sempre estão. (MANZINI, 1996, p. 185 Apud LANCILLOTTI, 2003, p. 10).

Para a Manzini (1996), a meta final da educação tem sido o trabalho. Embora várias políticas públicas tenham sido realizadas para a inclusão da PCD ao mercado de trabalho, pode-se observar que ainda há muitas barreiras no seu acesso e permanência. Infelizmente, questões como preconceito e a falta de reconhecimento das potencialidades das $\mathrm{PCD}$, ainda são notórias.

A Constituição Federal do Brasil, no seu artigo $7^{\circ}$, proíbe a discriminação na remuneração e nos critérios de admissão dos trabalhadores com deficiência. A Convenção sobre os Direitos da Pessoa com Deficiência assegura no seu artigo 23, condições de acessibilidade que garantem às PCD as mesmas condições de que gozam a população sem deficiência. 


\section{Apøe Ciênci@ Artigo}

apaeciencia.org.br/revista

Segundo os dados do censo do Instituto Brasileiro de Geografia e Estatística (IBGE), realizado no país em 2010, reside no país cerca de 45,6 milhões de pessoas com alguma deficiência, o que representa 23,9\% da população total (CARTILHA DO CENSO DE 2010, 2012)

Em 2010, cerca de 23,6\% da população com algum tipo de deficiência exercia ocupação profissional. Em contrapartida, a população de pessoas sem deficiência com ocupação profissional, era de 76,4\% (CARTILHA DO CENSO DE 2010, 2012).

É importante ressaltar a Lei de $\operatorname{Cotas}^{2}$ (8.213/91), estabelecida no Brasil há 25 anos, que contribui para aumentar a participação das PCD no mercado de trabalho, tal qual garante que as empresas com 100 ou mais funcionários, destinem de $2 \%$ a $5 \%$ das vagas às PCD. Todavia, apesar dessa legislação, observa-se que o número de PCD empregadas ainda é bem menor, se comparado às pessoas sem deficiência.

Segundo Teixeira (2010, apud FERREIRA, 2015), é compromisso não somente do governo, mas também das empresas a inclusão das PCD no mercado profissional. Para o autor, a contratação de pessoas com deficiência é uma questão de ética:

Além do mais, buscar trazer a diferença para dentro da empresa, combatendo o preconceito e reconhecendo a igualdade essencial entre as pessoas, é uma atitude que faz parte da postura ética a ser adotada como valor e prática nos negócios. Em decorrência dessa postura, os programas corporativos de valorização da diversidade estão sendo cada vez mais, introduzidos nas organizações como um componente positivo de integração social, que destaca a riqueza de talentos e capacitações de cada pessoa (TEIXEIRA, 2010, p. 72-73).

Mesmo de forma pequena, podemos visualizar um número muito baixo de empresas que têm a política e o interesse de contratar PCD. Parte desse problema, infelizmente, ainda se esbarra no preconceito. Todavia, esse aspecto não exclui a baixa oferta de vagas de emprego para PCD, assim como as dificuldades que encontram de interação pessoal no âmbito profissional, o tempo de permanência no emprego, a necessidade de formação profissional, dentre outros aspectos. Contudo, sabe-se que o acesso das PCD no mercado de trabalho existe, mesmo longe do ideal. Logo, acreditamos que as empresas que aderem a essa Lei de Cotas, estão oportunizando o desenvolvimento e as habilidades profissionais das PCD.

De acordo com Amaral:

\footnotetext{
${ }^{2}$ LEI № 8.213, de 24 de julho de 1991. Lei de Cotas - Para Pessoas Com Deficiência. Subseção II - Da Habilitação e da Reabilitação Profissional. Brasil, Planalto, 1991.
} 
Na sociedade capitalista o trabalho é visto, essencialmente, como possibilidades de inserção no circuito de produção-consumo [...] sem entrar pelo atalho do mito do "paraíso perdido" da era pré-industrial, ressalto apenas a perda significativa da possibilidade genérica de fruição da díada trabalho/prazer [...] este talvez seja o ponto principal, o resgate do papel do trabalho: seu potencial de elemento significativo, seja na auto-realização, seja na configuração da auto-estima, seja na independência econômica, na autonomia, no prazer presente no processo e no produto, na sensação de aceitação e "pertencimento" [...] enfim o resgate da visão do trabalho coo fonte de satisfação na vida das pessoas com deficiência. (AMARAL, 1944, p. 131 -132, apud LANCILLOTTI, 2013, p. 12).

A autora se preocupou em apontar a importância de resgatar o caráter do trabalho, longe da ótica alienada do capitalismo. O discurso do papel do trabalho como elemento importante para realização, aceitação e inclusão, também faz referência à cidadania, ou seja, é uma forma de qualquer cidadão participar da sociedade em que vive, produzindo algo para si e para os outros.

Para Lancillotti (2003), o ponto essencial é questionar se sob esse modelo é possível pensar e acreditar na possibilidade de auto-realização e integração efetiva das PCD à sociedade, pela via do trabalho.

Quando se fala de integração de pessoas com deficiência fala-se [...] de sua inserção no mundo do trabalho, uma vez que essa é uma privilegiada faceta da vida do cidadão. [...] A partir dessa ótica há que se pensar em todas as alternativas possíveis para que a inserção laboral de fato ocorra [...] esta parece ser uma das alternativas que contém em si a semente de maior satisfação de todos os protagonistas envolvidos, uma vez que possibilita a real inserção da pessoa num dos mais valorizados âmbitos da vida: o trabalho. (AMARAL, 1996, p. 165, apud LANCILLOTTI, 2013, p. 13).

A autora destaca que é preciso falar de integração de PCD no mundo do trabalho, vendo qualquer cidadão como capaz de ser valorizado e realizado nesse aspecto da sua vida.

O discurso sobre o trabalho, o encaminhamento das PCD para o trabalho, bem como a necessidade de formação profissional e as legislações que regem sobre esses assuntos, são temas muito extensos, logo algum recorte se impunha. Então, objetivo deste estudo recaiu sobre localizar e analisar produções científicas que narrassem sobre os temas: mercado de trabalho, no contexto das pessoas com deficiência e as ações da Apae nesse sentido. É importante ressaltar que o presente 


\section{Apøe Ciênciø Artigo}

apaeciencia.org.br/revista

texto faz parte do projeto de pesquisa: Educação Especial nas Unidades Educacionais da Rede Apaeana ${ }^{3}$.

Dessa maneira, iniciamos com o levantamento bibliográfico, mediante a busca eletrônica de trabalhos científicos, que narrassem sobre os temas acima mencionados. Para tanto, foram procurados documentos nas seguintes bases de dados: Scielo, Capes, Biblioteca Digital Brasileira de Teses e Dissertações e GT 15 da Anped.

A busca foi realizada em documentos nacionais, a princípio, sem delimitar um período. Durante esse levantamento, foram utilizadas as palavras recorte: trabalho e Apae; mercado de trabalho e Apae. Durante essa pré-análise, foram selecionadas apenas as bibliografias que levavam no título, nos resumos ou nas palavras-chave informações e palavras que narrassem a ligação do tema trabalho com a instituição Apae. Quando foram localizados documentos com um tema semelhante ao trabalho, como: ocupação profissional, inclusão laboral ou profissão, a palavra recorte Apae foi procurada ao longo do texto, para esclarecer se o documento dialogava com a proposta desta pesquisa.

Após um levantamento bibliográfico, poucos documentos foram encontrados sobre as palavras-chave já descritas. Apenas 13 trabalhos estavam relacionados ao tema desta pesquisa.

Em alguns bancos de dados, tal como a CAPES, nenhum documento relacionado ao tema foi localizado. Ao examinarmos a Biblioteca Digital Brasileira de Teses e Dissertações (IBICT), um trabalho foi encontrado, contrapondo-se ao banco de dados da SCIELO, que indicou 12 trabalhos relacionados ao tema da pesquisa.

Para Lakatos (2001, p. 29), a análise documental “[...] seria um conjunto de operações visando representar o conteúdo de um documento de forma diferente”. A análise e a interpretação dos documentos encontrados caracterizam a produção deste artigo.

\section{A APAE E A INCLUSÃO NO MERCADO DE TRABALHO}

Nessa perspectiva, com o intuito de atender as pessoas com deficiência aqui no Brasil, foi criada a Associação de Pais e Amigos dos Excepcionais (Apae) no ano de 1954, no Rio de Janeiro. A instituição "[...] caracteriza-se por ser uma organização social, cujo objetivo principal é promover

\footnotetext{
${ }^{3}$ Projeto de Educação Especial nas Unidades Educacionais da Rede Apaeana: Políticas de Inclusão, Aprendizagem e Desenvolvimento dos alunos com deficiência, que é desenvolvido pelo - GEPIEE/UFMS.
} 


\section{Apøe Ciênciø Artigo}

apaeciencia.org.br/revista

a atenção integral à pessoa com deficiência intelectual e múltipla.” (APAE, 2016). A instituição constitui uma rede de promoção e defesa de direitos das PCD, “[...] prestando serviços de educação, saúde e assistência social a quem deles necessita."

Segundo informações da Apae Brasil (2016), o Movimento Apaeano se expandiu por todo o país, atualmente os estados do Brasil compreendem 2.156 Apaes e entidades filiadas, coordenadas por 24 Federações Estaduais, abrangendo todos os estados brasileiros. Todas essas unidades formam uma rede filantrópica, que chegam a atender cerca de 250 mil pessoas com Deficiência Intelectual e Múltiplas diariamente. Tendo em vista a realidade de qualificação dessas pessoas em sentido pleno, a Apae oferece treinamento, capacitação e oportunidades para incluir Jovens e Adultos com deficiência, mostrando a eles sua capacidade produtiva e propiciando uma qualidade de vida, capaz de influenciar a vida pessoal e profissional, impactando na renda familiar e na valorização pessoal.

Nessa perspectiva, a elevada significância do trabalho na vida do homem, como elemento importante para a promoção do seu desenvolvimento, assim como a importância da inclusão de PCD no mercado de trabalho e a promoção das ações que a Apae presta às PCD, justifica-se a escolha dos temas desta investigação, além de levantar resultados para o projeto de pesquisa do GEPIEE/UFMS. Diante desses argumentos, este trabalho tem como finalidade, analisar os resumos de documentos científicos, que falem sobre os temas: trabalho, no contexto das PDC e ações da Apae. Posto isso, também ressaltaremos aqui a importância e a contribuição que a Apae tem promovido às PCD e à sociedade.

\section{PRODUÇÃO CIENTÍFICA SOBRE O MERCADO DE TRABALHO NAS APAES}

Para identificar os aspectos específicos que tratavam cada documento, uma outra análise foi iniciada nos trabalhos encontrados. Foi a partir da leitura do resumo dos 13 documentos, que se obteve maior clareza sobre o contexto do mercado de trabalho relacionado à Apae. Entretanto, realizar apenas a leitura do resumo de alguns estudos limitou as informações. Nesses casos, foi necessário dar continuidade à leitura do documento completo. O aspecto da leitura, nesse sentido, é muito importante. Almeida (2005) ressalta como a leitura propicia a ampliação dos horizontes e torna-se essencial nos estudos e na pesquisa. 


\section{Apøe Ciênci@ Artigo}

apaeciencia.org.br/revista

Logo, no decorrer desta análise, o tema trabalho e Apae foi apresentado em diferentes perspectivas. As temáticas encontradas nos documentos foram organizadas como se segue, resumidamente, indicando as suas fontes:

a) Programas para a formação profissional dos alunos da Apae - Johann (2011).

b) Processo de inclusão e preparação para o mercado de trabalho na Rede Apaeana e Lei de Cotas - Ferreira (2015), Silva (2014), Lima, Alves, Silva e Petrili (2012), Furtado (2013).

c) Programa de formação de professores da APAE para capacitação ao mercado de trabalho - Mourão e Borges-Andrade (2005) e Costa, Comello, Tette, Rezende e Nepomuceno (2011).

d) Estudo de caso na Apae - A relação do trabalho com as pessoas com deficiência - Ilha (2007).

e) A pessoa com deficiência no Mercado de Trabalho - Cunha, Marafon, Bonvicini e Souza (2015).

f) A inserção no mercado de trabalho nos cursos profissionalizantes da Apae - Santos (2013).

g) A inclusão e exclusão no mercado de trabalho, avanços e desafios - Rosa e SilvaPerdigão (2014) e Bezerra e Silva (2010) e Barbosa (2014).

Apesar da pequena quantidade de documentos sobre o tema deste trabalho, faz-se necessário ressaltar pontos essenciais de cada artigo. Essa análise pretende ser um resumo dos 13 documentos anteriormente citados, nos quais se apresenta o contexto da Apae e o seu trabalho nesses estudos.

No primeiro tema, o autor Johann (2011) faz uma retrospectiva ao surgimento da Educação Especial, dando destaque ao surgimento da instituição Apae e a Federação Nacional das Apaes (FENAPAES). O autor ressaltou a valorização da qualificação para a formação de trabalhadores autônomos, criativos e responsáveis. Para isso, Johann analisou na sua dissertação, o programa de Educação Profissional da Apae, denominado PECT - Processo de Educação Profissional e Colocação no Mercado de Trabalho, fazendo um levantamento de quantos alunos já tinham sido atendidos pelo programa e, consequentemente, preparados para o mercado de trabalho.

Em relação ao tema processo de inclusão e preparação para o mercado de trabalho na Rede Apaeana, três documentos foram encontrados. 


\section{Apøe Ciênci@ Artigo}

O trabalho de conclusão de curso de Ferreira (2015) surgiu após um estágio na Apae de Laranjeiras, Serra. O texto discorreu sobre o ingresso das PCD no mercado profissional, ressaltando algumas dificuldades nesse processo, como o preconceito, que ainda é um fator determinante para impedir o ingresso profissional. Além disso, Ferreira (2015) investigou sobre o cumprimento de políticas públicas e afirmou a necessidade de qualificação das PCD. A autora apresentou a importância da Apae diante das problemáticas expostas acima, definindo-a como uma instituição que acolhe e dá atenção integral às PCD, além de prepará-las para a vida pessoal e profissional.

A dissertação de mestrado de Silva (2014), realizada em Minas Gerais, discursa sobre os desafios da gestão empresarial para atuar no cenário da inserção PCD no mercado profissional. Sua pesquisa evidenciou a importância de instituições especializadas, como a Apae. A autora ainda destacou que, entre três motivos principais para a contratação de trabalho, os gestores contratam PCD por influência de uma instituição especializada, como por exemplo, a Apae.

Os autores Lima, Alves, Silva e Petrili (2012) discutiram no seu artigo, os aspectos de ensino-aprendizagem para a atuação profissional, refletindo sobre como se dá a aquisição e assimilação de novos conteúdos. Este trabalho foi realizado na Apae de Gurupi - Tocantins. Fizeram parte desse processo: as empresas empregadoras de PCD; gestores; professores e alunos da instituição. Ao observarem o processo de desempenho dos funcionários com deficiência, os autores ressaltaram o direito a profissionalização, a necessidade de acompanhamento e a possível superação das limitações das PCD, dentre outros aspectos.

Furtado (2013) destacou a importância do trabalho na construção da identidade humana. Logo, a sua dissertação realizou entrevistas com PCD empregadas e desempregadas, bem como seus familiares, a fim de coletar relatos de experiência, sobre a satisfação de ingressar na vida profissional, a oferta de empregos, a profissionalização, dentre outros fatores. Dos 35 entrevistados nesta pesquisa, apenas uma pessoa destacou os serviços prestados a ela pela Apae, especificamente na área da saúde. Todavia, a autora não enfatiza a instituição no seu texto.

Mourão e Borges-Andrade (2005) avaliaram no seu artigo, um programa público de capacitação ${ }^{4}$, a partir da análise de treinamentos realizados com professores da Apae, visando aumentar o índice de pessoas inseridas no mercado de trabalho. O objetivo dos autores era identificar se esse treinamento gerou impacto no desempenho dos trabalhadores, nas oficinas de

\footnotetext{
${ }^{4}$ Treinamentos realizados no âmbito do Plano Nacional de Qualificação de Trabalhadores/Planfor do Ministério do Trabalho e Emprego/MTE.
} 


\section{Apøe Ciênciø Artigo}

apaeciencia.org.br/revista

formação e foi oferecido na geração de empregos. Após avaliar professores treinados, seus chefes, seus pares e os pais de seus alunos, conclui-se que houve impacto do treinamento. As Apaes que aderiram ao programa de capacitação tiveram um resultado melhor com os seus alunos trabalhadores, no aspecto da aplicação deles no trabalho e na vida pessoal.

Segundo Costa, Comello, Tette, Rezende e Nepomuceno (2011), a falta de qualificação das PCD, é um dos fatores de impedimento para a contratação dessas pessoas por algumas empresas. Nesse sentido, os autores investigaram cursos para a qualificação profissional de PCD, oferecida pelas Apaes de cinco cidades da região de Minas Gerais e quais aspectos contribuíam para a qualificação deles. Conclui-se que, no contexto de instituição especializada, a Apae promove impacto no desenvolvimento dos seus alunos, oportunizando cursos vantajosos em relação a uma atividade que pode ser profissional até como seu desenvolvimento pessoal, saúde e educação. Para os autores "o processo de qualificação profissional se configura em uma teia de tensões, muitas vezes contraditórias, abrangendo diferentes visões e expectativas por parte dos atores envolvidos, como a FENAPAE, as instituições, as famílias e as próprias pessoas com deficiência". (COSTA; COMELLO; TETTE; REZENDE; NEPOMUCENO, 2011, p. 13).

Para Ilha (2007, p. 1), a importância da inclusão de PCD na atividade é um "aspecto muito importante para o processo de inclusão social”. A autora descreve no seu artigo, uma investigação dos aspectos do projeto "Educação de adolescentes e adultos com deficiência em associações de Educação Especial", o qual tem como objetivo proporcionar aos acadêmicos do Curso de Educação Especial conhecimentos teóricos e práticos a cerca do trabalho pedagógico com adolescentes e adultos em Instituições especializadas. Para ter referência e propor uma pesquisa qualitativa, a autora realizou o seu trabalho na instituição Apae de Londrina, que também participa do projeto anteriormente citado.

Os autores Cunha, Marafon, Bonvicini e Souza, (2015) apontam no seu estudo descritivo, benefícios obtidos pela inserção das PCD no mercado de trabalho e os avanços que a inclusão promove no seu cotidiano. Os autores introduzem o texto apontando conceitos sobre deficiência e suas características. Apesar da participação da Apae apenas como referência no texto, este artigo foi aqui analisado, porque apresenta a necessidade de inclusão das PCD no trabalho, bem como, os desafios que empresas e sociedade enfrentam para reconhecerem o potencial das PCD, lutando contra as barreiras do preconceito. 


\section{Apøe Ciênci@ Artigo}

Na sua dissertação de mestrado, Santos (2013, p. 3) investigou pela pesquisa quantitativa e qualitativa, a situação da empregabilidade de PCD, a partir dos "Centros de Formação Profissional”. $\mathrm{O}$ autor teve como objetivo verificar o processo de preparo para o trabalho nas instituições profissionalizantes. A Apae se destaca no texto como uma das primeiras instituições em realizar oficinas para PCD, além de ser uma das maiores redes de atendimento às PCD do Brasil e do mundo na sua área de atuação (FENAPAES, 2016). Para o autor, a Apae não é rede profissionalizante, mas, um veículo que treina seus alunos para o futuro, para que ele possa se relacionar com tudo ao seu redor.

Dentro da temática concernente à inclusão e exclusão no mercado de trabalho e aos avanços e desafios, três trabalhos serão analisados.

Rosa e Perdigão (2014) discutem sobre a inclusão e exclusão de PCD no mercado de trabalho, bem como os fatores educacionais, sociais, destacando orientações legais, concepções e práticas das relações de trabalho no capitalismo contemporâneo. A partir da seleção de 17 (dezessete) trabalhos científicos, nas áreas de Educação, Psicologia e Administração, os autores pontuam, no texto, análises sobre os referidos trabalhos, ressaltando avanços e desafios sobre a inclusão no mercado de trabalho.

Segundo Bezerra e Silva (2010, p. 17) "um dos argumentos mais utilizados para a não inserção de pessoas com deficiência intelectual em empresas é a sua limitação cognitiva." Para Tomasini (1996 apud BEZERRA; SILVA, 2010), sobre o preconceito ainda presente na sociedade, acredita-se que "a limitação intelectual dessas pessoas é também usada pelos educadores e pela comunidade como um todo como fator impeditivo", além da incapacidade de "aprendizagem de conteúdos mais complexos”, mostrando-se claramente. Bezerra e Silva esclarecem no seu artigo que, para que o trabalho promova a construção de cidadania nas PCD, a sociedade deve ir em busca de "arranjos instrucionais que permitam que esse público seja inserido no mercado de trabalho" (BEZERRA; SILVA 2010, p. 18). Nesse sentido, os autores destacam no texto a participação da Apae nessas inquietudes e concluem definindo que a participação das PCD na instituição é importante parte do processo para inclusão no trabalho.

Barbosa (2014, p. 8), no seu artigo de conclusão de curso, buscou compreender o processo da inclusão atualmente, dando visibilidade aos desafios enfrentados pelas pessoas com deficiência, bem como, o conhecimento e a percepção das pessoas com deficiência sobre as políticas e legislações que impactam sua inclusão no mercado de trabalho. $\mathrm{O}$ autor reconhece os avanços e as 


\section{Apøe Ciênciø Artigo}

apaeciencia.org.br/revista

conquistas alcançados quanto à inserção das PCD no mercado de trabalho, porém destaca alguns desafios, como: "pouco interesse de alguns empregadores diante das habilidades e potencialidades das PCD; salários baixos e a presença do preconceito no ambiente de trabalho" (BARBOSA, 2014, p. 80). No decorrer do texto, o autor destaca a Apae como uma instituição de referência no segmento das PCD, com o intuito de melhorar sua qualidade de vida, na área de educação e de saúde.

\section{CONSIDERAÇÕES FINAIS}

Apesar das limitações deste estudo, especialmente no que se refere ao pequeno número de documentos analisados, tratou-se de compreender a inserção das PCD no mercado de trabalho, refletindo sobre as ações que a Apae promove nesse sentido.

Observa-se que o tema integração ou inclusão fazem parte do discurso frequente no texto e nos documentos analisados. É importante ressaltar que essa é uma temática bem discutida atualmente. Porém, a nossa sociedade capitalista ainda promove a exclusão, principalmente em relação às minorias, incluindo as PCD. Portanto, pode-se afirmar que a dificuldade de trabalho atualmente, não é um problema exclusivo das PCD, mas sim, um problema inserção no mercado de muitos trabalhadores. Reconhecemos que o índice elevado de desemprego e instituições que oferecem vagas de emprego para PCD ainda está longe de atender à demanda de trabalho para PCD.

Outra observação é que a legislação criada para promover o acesso da PCD ao trabalho reflete contradições na sua aplicação. Há que se ponderar que houve conquistas para a Educação Especial e PCD com toda a legislação feita no país. Observa-se, também, um número maior de autores debatendo sobre as temáticas alusivas ao trabalho, como: o processo de inclusão no mercado de trabalho, a necessidade de programas de capacitação profissional, inclusão e exclusão.

Nessa perspectiva, é notória na maioria dos 13 documentos analisados, a importância das ações das Apaes. Poucos foram os documentos que não destacaram a instituição como um veículo necessário de apoio e ensino especializado às PCD, lutando em favor dos seus direitos e do bemestar de cada etapa da sua vida.

Nos textos analisados, a Apae também ganhou destaque como órgão de referência no apoio às PCD, ao encaminhamento ao mercado de trabalho, propiciando ações profissionais em vários ofícios, a fim de desenvolver suas atividades sociais e potencializar as aptidões de cada 


\section{Apøe Ciênci@ Artigo}

apaeciencia.org.br/revista

aprendiz/aluno. Ressalta-se, portanto, que a existência da Apae e as suas ações desenvolvidas em benefício da PCD e a sociedade, estão promovendo pesquisas e estudos, como as que aqui foram citadas.

Apesar de escassas, as publicações que narram sobre as ações da Apae e o mercado de trabalho têm contribuído com diversos aspectos, dentre eles: identificação da atual situação da inclusão das PCD no mercado de trabalho; estudos na área de formação para o trabalho; desafios de PCD na vida profissional - inclusão, cumprimento da legislação, investimento das empresas nas PCD, qualificação profissional das PCD - a luta contra preconceito social e no trabalho, dentre outros aspectos. Ademais, o presente artigo demonstra como as unidades apaeanas contribuem para os promove avanços na área, mediante as pesquisas realizadas no contexto da Apae. Apesar de um estudo pequeno e iniciante, este artigo traça um caminho promissor na perspectiva de continuar as análises sobre trabalho e Apae.

Consideramos que os resultados da presente investigação apontam, ainda, para a importância de discutir-se sobre a inclusão de PCD no trabalho. Partindo do pressuposto de que o trabalho foi e continua sendo a base do ser social e é uma das principais formas de se promover o desenvolvimento social, pessoal e a inclusão, pode-se afirmar que discutir sobre essa área, tem sido uma temática muito relevante atualmente. 


\section{Apøe Ciênci@ Artigo}

apaeciencia.org.br/revista

\section{REFERÊNCIAS}

BRASIL. Lei de Diretrizes e Bases da Educação Nacional: Lei no 9394 de 20 de dezembro de 1996. Brasília: Senado Federal. Disponível em: www.planalto.gov.br> Acesso em 07 nov. 2016. ALMEIDA, C. E. M. Educação especial nos cursos de Licenciatura de Mato Grosso do Sul. Orientador: Mariluce Bitta 2005. ? 167 f. Dissertação (Mestrado em Educação) - Universidade Católica Dom Bosco, Campo Grande, 2005.

AMARAL, L. A. Mercado de trabalho e deficiência. Revista Brasileira de Educação Especial, Piracicaba, v. I, n. 2, p. 127-136, 1994.

APAE BRASIL. 2016. Disponível em: <http://apae.com.br/ > Acesso em: 14 dez. 2016. APAE DE MINAS GERAIS. Reflexões acerca da prática de colocação de pessoas com deficiência intelectual no mercado de trabalho na modalidade de colocação seletiva nas Apaes de Minas Gerais. 2011. Disponível em: https://www.uniapaemg.org.br/wpcontent/uploads/2018/04/inclusao_trabalho_renda.pdf, Acesso em: 2/04/2020.

BARBOSA, P. H. A pessoa com deficiência no mercado de trabalho: avanços e desafios no cenário contemporâneo. Fortaleza: Centro De Ensino Superior Do Ceará - Faculdade Cearense, 2014.

BENJAMIN, J. Inclusão no trabalho de pessoas com deficiência: um estudo da Apae de Barcarena-PA. 2013. Disponível em: http://repositorio.ufpa.br/jspui/handle/2011/4191, Acesso em: 2/04/2020.

BEZERRA, S. S; SILVA, M. H. D. Reflexões acerca da prática de colocação de pessoas com deficiência intelectual no mercado de trabalho na modalidade de colocação seletiva nas APAES de Minas Gerais. Belo Horizonte - Minas Gerais: Cadernos da CAADE, 2010. BRASIL. Constituição da República Federativa do Brasil de 1988. Disponível em: < https://www.planalto.gov.br/ccivil_03/constituicao/constituicao.htm> Acesso em: 20/11/2016 BRASIL. Cartilha do censo de 2010 - Pessoas com Deficiência. Brasília: SDH-PR/SNPD, 2012. BRASIL. Lei no 8.213, de 24 de julho de 1991. Presidência da República Casa Civil Subchefia para Assuntos Jurídicos. Brasil: Planalto, 1991.

BRASIL. Manual de Orientação: Programa de Implantação de Sala de Recursos Multifuncionais. Brasília: Ministério da Educação, 2010.

COSTA, M. C. A; COMELLO, D. M; TETTE, R. P. G; REZENDE, M. G. R; NEPOMUCENO, M. F. Inclusão Social pelo Trabalho: a Qualificação Profissional para as Pessoa com Deficiência Intelectual. Revista Interinstitucional de Psicologia, São João del-Rei, v. 4, n. 2, p. 200 - 214, juldez. 2011.

CUNHA, E. L; MARAFON, A. C. F; BONVICINI, C. R; SOUSA, M. M. R. Pessoa com Deficiência Intelectual Inserida no Mercado de Trabalho. Revista Brasileira de Gestão e Engenharia, São Gotardo, v. 21, n. 4, p. 59 - 72, jan-jun 2015.

DALLABRIDA, A. M. As famílias e a classe especial em um colégio de elite. Revista Brasileira de Educação Especial, Santa Catarina, v. 13, n. 3, p. 459 - 478, dez, 2007.

FERREIRA, E. A. A inserção de pessoas com deficiência no mercado de trabalho. Vitória: Faculdade Católica Salesiana do Espírito Santo, 2015.

FURTADO, Adelaine Vianna. Pessoas com deficiência intelectual e a inclusão no mercado de trabalho. Orientador: Nara Liana Pereira Silva. 2013. 111 f. Dissertação (Mestrado em Psicologia) - Universidade Federal de Juiz de Fora, Juiz de Fora-MG, Brasil. 2013.

FURTADO, Adelaine Vianna; SILVA, Nara Liana Pereira. Trabalho e Pessoas com Deficiência Intelectual: Análise da Produção Científica. Universidade Federal de Juiz de Fora, Juiz de Fora- 


\section{Apøe Ciênciø Artigo}

apaeciencia.org.br/revista

MG, Brasil. Revista Brasileira de Orientação Profissional, Juiz de Fora, v. 15, n. 2, p. 213 - 223, mês abreviado 2014,

ILHA, T. F. O mercado de trabalho no contexto de pessoas com necessidades especiais. IV

Congresso Brasileiro Multidisciplinar de Educação Especial. Londrina - PR, 2007.

JOHANN, J. Programas de Educação Profissional na Apae de Toledo - Paraná. Orientador:

Ireni Marilene Zago Figueiredo. 2011. f. Dissertação (Mestrado em Educação) - Universidade

Estadual do Oeste do Paraná - UNIOESTE, Cascavel - Paraná, 2011

LAKATOS, Eva Maria. Metodologia do trabalho científico: procedimentos básicos, pesquisa bibliográfica, projeto e relatório, publicações e trabalhos científicos. 6. ed. São Paulo: Atlas, 2001.

LANCILLOTTI, S. S. P. Deficiência e o trabalho: redimensionando o singular no contexto universal. Campina - SP: Autores Associados, 2003. (Coleção polêmicas do nosso tempo)

LIMA, R. D.; ALVES, M. L. S.; SILVA, N. E. A.; PETRILLI, L. T. A pessoa com deficiência intelectual no mercado de trabalho em Gurupi - TO: Um estudo de caso. Revista Cereus, Gurupi, v. 4, n. 2, p. 376 - 381, ago. 2012.

MACIEL, M.R.C. Portadores de deficiência: a questão da inclusão. São Paulo Perspec., São Paulo, v. 14, n. 2, p. 51 - 56, abr-jun. 2000. Disponível em <

http://www.scielo.br/scielo.php?script=sci_arttext\&pid=S0102-88392000000200008 >. Acesso em: 2/04/2020.

MANZINI, E. J. Profissionalização de indivíduos portadores de deficiência mental: visão do agente institucional e visão do egresso. Temas em Educação Especial, São Carlos, n. 3, p. 184 - 216, 1996.

MOURÃO, L; BORGES-ANDRADE, J. E. Avaliação de Programas Públicos de Treinamento: um estudo sobre o impacto no trabalho e na geração de emprego. 2005. Disponível em:

http://www.scielo.br/scielo.php?script=sci_arttext\&pid=S1984-92302005000200001 Acesso em: 2/04/2020.

ORGANIZAÇÃO DAS NAÇÕES UNIDAS. DECLARAÇÃO UNIVERSAL DOS DIREITOS

HUMANOS. UNIC-RIO. 2009. Disponível em: < http://www.onu.org.br/img/2014/09/DUDH.pdf $>$ Acesso em 20 nov. 2016.

ROSA, F. G. S.; SILVA-PERDIGÃO, M. G. O que dizem as pesquisas sobre a inclusão da pessoa com deficiência no trabalho. VI Encontro Nacional de Pesquisadores da Educação Especial, São Carlos - UFSCar, v. 01. p. 1-13. 2014.

SANTOS. A. C. Preparação e inserção da pessoa com deficiência no mercado de trabalho. 2013. f. Dissertação de Mestrado. Universidade Federal De São Carlos. São Carlos - SP - 2013 SILVA, L. M. A inserção de pessoas com deficiência em pequenas empresas: um estudo sobre a relação vincular e as concepções de deficiência dos gestores. Orientador: Maria Nivalda de Carvalho-Freitas. 2014. 139 f. Dissertação (Mestrado em Psicologia) - Universidade Federal de São João Del-Rei (UFSJ), São João del-Rei, 2014.

TEIXEIRA, M. C. A. Políticas públicas para pessoas com deficiência no Brasil. Orientador: Mario Aquino Alves. 2010. 131 f. Dissertação (Mestrado em Administração de Empresas) - Escola de Administração de Empresas de São Paulo, Fundação Getúlio Vargas, São Paulo, 2010.

Disponível em <

http://bibliotecadigital.fgv.br/dspace/bitstream/handle/10438/4778/61080100037.pdf?sequence=1\&i sAllowed $=\mathrm{y}>$. Acesso em: 12/01/2020. 


\section{Apøe Ciênciø Artigo}

apaeciencia.org.br/revista

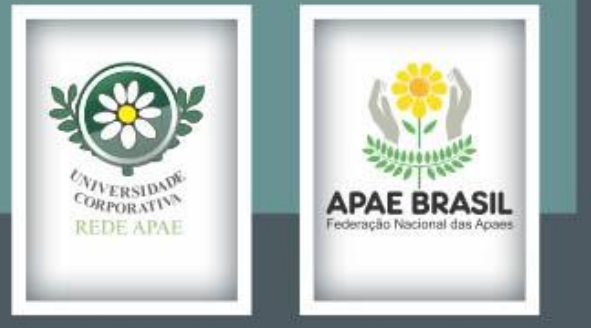

TOMASINI, M. E. A. Trabalho e deficiência mental: uma questão a ser repensada. Revista

Brasileira de Educação Especial, Piracicaba, v. 3, n. 4, p. 91-110, 1996.

WERNECK, C. Sociedade Inclusiva: Quem cabe no seu "todos". Rio de Janeiro:WVA, 1999. 